\title{
The Individual Travel Cost Method with Consumer-Specific Values of Travel Time Savings
}

\author{
Mikołaj Czajkowski $^{1}$ D $\cdot$ Marek Giergiczny $^{1} \cdot$ Jakub Kronenberg $^{2} \cdot$ Jeffrey Englin $^{3}$
}

Accepted: 10 June 2019 / Published online: 24 June 2019

(c) The Author(s) 2019

\begin{abstract}
The treatment of the opportunity cost of travel time in travel cost models has been an area of research interest for many decades. Our analysis develops a methodology to combine the travel distance and travel time data with respondent-specific estimates of the value of travel time savings (VTTS). The individual VTTS are elicited with the use of discrete choice stated preference methods. The travel time valuation procedure is integrated into the travel cost valuation exercise to create a two-equation structural model of site valuation. Since the travel time equation of the structural model incorporates individual preference heterogeneity, the full structure model provides a travel cost site demand model based upon individualized values of time. The methodology is illustrated in a study of recreational birdwatching, more specifically, visits to a 'stork village' in Poland. We show that the usual practice of basing respondents' VTTS on 1/3 of their wage rate is largely unfounded and propose alternatives-including a separate component of the travel cost survey aimed at valuation of respondents' VTTS or, as a second best, asking if they wish if their journey was shorter and for those who do-use full hourly wage as an indicator of their VTTS.
\end{abstract}

Keywords Opportunity cost of travel time - Individual-specific values of travel time savings · Travel cost method - Discrete choice experiment - Integration of valuation methods $\cdot$ Recreational birdwatching

JEL Classification Q26·Q51 - Q57

Mikołaj Czajkowski

mc@uw.edu.pl

Marek Giergiczny

mgiergiczny@wne.uw.edu.pl

Jakub Kronenberg

kronenbe@uni.lodz.pl

Jeffrey Englin

Jeffrey.Englin@asu.edu

1 Department of Economics, University of Warsaw, Długa 44/50, 00-241 Warsaw, Poland

2 Faculty of Economics and Sociology, University of Lodz, P.O.W. 3/5, 90-255 Lodz, Poland

3 Morrison School of Agribusiness, Arizona State University, 7171 E. Sonoran Arroyo Mall, Mesa, AZ 85212, USA 


\section{Introduction}

This analysis proposes a structural model of the travel cost demand approach (TCM) that includes two components. One component is used to estimate the value of travel time for each individual in the sample. The second component incorporates that value of travel time into the travel cost variable that is used in the estimation of the site demand. While the travel cost demand curve is estimated using the widely applied count methodology, the travel time component of the model is based on a discrete choice stated preference method. Our approach avoids arbitrary assumptions about an individual's value of time in an appealing way. It also allows quite intricate valuations since the stated preference portion of the model can accommodate a wide range of travel modes, time constraints, family situations and other considerations that can affect the value of one's time when traveling for recreation.

The individual level approach to valuing travel time utilized in this analysis is made possible by relatively recent advances in modeling preference heterogeneity in stated preference studies. The advances allow the derivation of posterior estimates of each individual's taste parameters. We argue that utilizing individual-specific values of travel time savings, based on respondents' stated preferences, provides a feasible method for empirically incorporating the value of travel time into travel cost demand studies. Through an empirical illustration we show that the proposed approach is tractable. All it requires is the inclusion of only a few discrete choice experiment (DCE) questions in a TCM survey and a proper econometric treatment.

Our results show that using arbitrary assumptions concerning individuals' value of travel time savings (VTTS) equal to a given share of their wage rate (e.g., 1/3) are largely unfounded. First of all, nearly half of respondents say they do not wish their journey to the site was shorter, indicating positive utility of leisure travel. Those who wished to shorten the journey were willing to pay amounts which appear only mildly correlated with their estimated wage rates. Overall, the average consumer surplus per trip calculated from the model with individual-specific VTTS were the closest to the model which used respondents' full wage rate included for respondents who said they wish their journey was shorter (and zero for others). We suggest using this approach as the second best, in the case eliciting individual specific VTTS was not possible.

\subsection{Economics of Time: What Do We Know}

In 1965 Becker postulated that "time can be converted into money". The basic idea is that people choose how much labor to supply, given a constraint that total time available is divided among work, leisure, and travel. At its bare bones, this model implies that travel time is valued at the after-tax wage rate. This is because the Becker model assumes that time can be transferred freely between work and leisure, so any marginal savings in travel time can be used to increase labor income. This model has been expanded in many directions. A common starting point is DeSerpa (1971). This model assumes that utility is affected by commodity bundles $X=\left(X_{1}, \ldots, X_{n}, T_{1}, \ldots, T_{n}\right)$ where $X_{i}$ denotes some quantity of the $i$-th good, while $T_{i}$ denotes the amount of time allocated to the $i$-th good. These goods can include both travel to a recreational site and time onsite. $T_{w}$ denotes time spent at work (which may increase or decrease utility). Each activity has a minimum time requirement $\bar{T}$ (hence constraint $T_{i} \geq \bar{T}$ ). There is also an overall time constraint $T_{w}+\sum T_{i} \leq T^{0}$. 
The budget constraint is $P_{i} X_{i} \leq Y+w T_{w}$, where $Y$ is unearned income. As a result, the problem can be stated as:

$$
\max U\left(X_{1}, \ldots, X_{n}, T_{1}, \ldots T_{n}\right) \text { s.t. }\left\{\begin{array}{c}
P_{i} X_{i} \leq Y+w T_{w} \\
T_{w}+\sum T_{i} \leq T^{0} \\
\sum_{i=1}^{n} K_{i}\left(T_{i}-\bar{T}\right) \geq 0
\end{array}\right.
$$

This problem can be solved by formulating a Lagrangian function, in which each constraint is associated with a Lagrange multiplier indicating how tight it is (i.e., the rate at which utility could be increased by relaxing it a little). Let $\lambda, \mu$, and $\kappa$ be the Lagrangian multipliers for the budget constraint, the overall time constraint, and the activity-specific time constraints, respectively. The solution to the optimization problem yields:

$$
\begin{gathered}
\frac{\mu}{\lambda}=w+\frac{\partial U / \partial T_{w}}{\lambda} \\
\left(T_{i}-\bar{T}\right) \kappa_{i}=0, \kappa_{i} \geq 0 \\
\frac{\kappa_{i}}{\lambda}=w+\frac{\partial U / \partial T_{w}}{\lambda}-\frac{\partial U / \partial T_{i}}{\lambda}
\end{gathered}
$$

Equation (2) states that value of time as a personal resource (or simply value of leisure) equals wage rate plus the value of utility from work. If $T_{i}$ in Eq. (3) is not restricted to its minimum then by the virtue of complementary slackness condition its multiplier would be zero. Which in turn implies that VTTS $=0$ and that $\frac{\partial U / \partial T_{i}}{\lambda}=w+\frac{\partial U / \partial T_{w}}{\lambda}$, that is, the value of marginal utility from the activity $i$ would be equal to value of leisure. In other words, if a person spends on an activity more time than the minimum required (the constraint $\sum_{i=1}^{n} \kappa_{i}\left(T_{i}-\bar{T}\right) \geq 0$ is not binding), such activity would be what DeSerpa (1971) calls a pure leisure good and its value equals to the value of time as a resource. On the other hand, if $\sum_{i=1}^{n} \kappa_{i}\left(T_{i}-\bar{T}\right)=0$ then $\kappa_{i} / \lambda$ can be interpreted as value of time saved (VTTS) in the activity $i$.

Most work in the transportation field assumes traveling is a means to an end and travel time is a disutility to be minimized. However, in the recent years new concepts emerged, including the so-called positive utility of travel, which suggests that travel can provide benefits and may be motivated by factors beyond reaching activity destinations (see, e.g., Mokhtarian and Salomon 2001; Mokhtarian 2005). Positive utility of travel implies that $\partial U / \partial T_{i}$ is positive. In the extreme case, if positive utility of time offsets $w+\frac{\partial U / \partial T_{w}}{\lambda}$ then VTTS would be zero. However, note that VTTS $=0$ does not mean that the value of time is zero.

Time is scarce and the time spent on traveling to the site as well as the time spent on the site is time that could have been devoted to other activities. The value of those lost opportunities is the time cost of the trip. It is important to distinguish between VTTS and the value of time in terms of lost opportunities. If the main goal of the analysis was to estimate benefits from a new road or any other public investment that would result in time savings then the analysis should focus on monetizing benefits from time saved. However, if the goal is to estimate consumer surplus from visiting a given site then the analysis should focus on estimating the alternative cost of time. Unfortunately, in the cases when $\frac{\partial U / \partial T_{i}}{\lambda}>0$, VTTS 
will underestimate the true value of time and the more similar the value of travel is to the value of time on-site, the larger the discrepancy between VTTS and the value of time in terms of lost opportunities will be.

\subsection{Valuing the Opportunity Cost of Travel Time in Recreation Demand Models: Previous Research}

The incorporation of the value of travel time in the TCM studies has been a source of concern since the earliest applications of this method (e.g., Clawson and Knetsch 1966; Johnson 1966). Researchers disagreed not only about how much the travel time is worth but also whether it should be included it in the model at all. Cesario (1976) provided an early cogent discussion of the incorporation of the value of time into travel cost models. Despite the decades of research into the value of time, Randall's (1994) observation that "the cost of travel time remains an empirical mystery" remains valid and estimating the value of travel time (or, in most cases, rather the opportunity cost of time) remains a frequently discussed problem in the literature on TCM (e.g., Fletcher et al. 1990; Garrod and Willis 1999; Hanley and Barbier 2009).

Early on McConnell (1975) stressed the need to estimate the value of time before incorporating it in the demand function. However, uncovering the rate of substitution between money and time was long considered empirically intractable (as these trade-offs are endogenous and unobservable), even if conceptually possible. Cesario's (1976) suggestion that commuter's travel time values of $25-50 \%$ of an individual's wage rate was widely adopted. Using a fraction of wage rate has remained probably the most common approach, with the compromise value of 33\% being the most broadly accepted level (Hellerstein and Mendelsohn 1993; Englin and Cameron 1996; Garrod and Willis 1999; Gürlük and Rehber 2008; Egan et al. 2009; Huhtala and Lankia 2012). Critics of the wage-based approach note that it makes little sense for those without reported wages, the method would suggest their marginal utility of time is zero. That is clearly not the case (Feather and Shaw 1999; Parsons 2003). ${ }^{1}$

Englin and Shonkwiler (1995) developed a model linking a count travel cost to a confirmatory factor analytic model. The confirmatory factor analytic portion allowed a travel time value to be imputed for each individual and incorporated into the cost of travel. In a further development, Feather and Shaw (1999) used shadow wages (the values of extra units of leisure time) as the opportunity cost of travel time and compared this with previous approaches (using a fraction of wage rate and hedonic wage equations). On average, their estimates were better adjusted to the observed wage rates for different employment categories of respondents, compared with the wage rate predicted by the hedonic model.

Recent work has focused on the relationship between one's work and life schedule and the value of time in recreational travel. The early discussion of these issues was put forth by Bockstael et al. (1987) who proposed a general framework on how to incorporate time in TCM studies, based on insights from the labor literature. Demand for time depends on whether an individual can freely substitute recreation for work (interior solution) or has fixed work hours (corner solution). Most recently, Larson and Lew

\footnotetext{
1 Notably, the transportation literature focusing on the estimation of the value of time has moved on from the rough approach of taking $33 \%$ of wage to more fine-tuned estimates taking into account, among other things, trip purpose, transport mode and difference between drivers and passengers (e.g., Börjesson and Eliasson 2014; Sartori et al. 2014; Mouter and Chorus 2016).
} 
(2014) empirically implemented a system of joint labor-recreation equations to capture these effects. Palmquist et al. (2010) employed a joint revealed stated preference approach to deal with fundamental lack of substitutability of recreation time for other forms of time. Both of these efforts seek a structural analysis of the value of time that looks at the relationship between the demand for time and hence value and flexibility to substitute time.

A second recent strand of work has focused on revealed valuations of travel time. Fezzi et al. (2014) utilized a natural experiment where recreationists had a choice of a toll road which was faster or not paying a toll and taking more time to reach the recreation site. This is a novel approach and very robust but it is also specific to a particular site and so will be subject to the usual limitations if the values are transferred to other settings. Wolff (2014) utilized speeding behavior as a function of gasoline price to identify the value of time. This is also revealed preference approach and so is excellent for the area studied but again the values must be transferred to use in other settings.

Early suggestions to combine TCM with contingent valuation or contingent behavior questions (Cameron 1992a, b; Adamowicz et al. 1994; Englin and Cameron 1996) explored the methodological issues without paying specific attention to the opportunity cost of time. For example, Englin and Cameron (1996) added contingent behavior questions to a TCM study but these questions referred to general trip costs and not specifically to the opportunity cost of time. Nevertheless, such an approach makes it possible to impose exogenously varying travel costs and could be applied to opportunity cost of time too. Álvarez-Farizo et al. (2001) adopted contingent valuation to estimate the value of leisure time for use in recreational models and confirmed a significant variation in leisure time values. Building on Shaw (1992), Casey et al. (1995) offered an alternative approach, indicating that individual preferences regarding time are better reflected by the opportunity costs of time associated with a particular aspect of recreation than the wage. After all, the latter measures the trade-off between work and leisure more generally. They complemented a standard travel cost survey with a contingent valuation question about peoples' willingness to accept compensation to forgo a precisely defined recreational experience and used these results to derive the value of leisure time. Ovaskainen et al. (2012) directly elicited a stated value of time using a contingent valuation survey. Finally, Lloyd-Smith et al. (2019) in the context of recreation demand for fishing trips found that individual value of leisure time is substantially different from one's implied wage rate.

In light of the above challenges of incorporating meaningful estimates of the opportunity cost of time into recreational demand models, in what follows we propose to combine TCM with a DCE that would indicate how much each respondent values travel time. Compared to most of the above ideas, ours is more flexible and it is very precise in that we obtain specific estimates on the opportunity cost of time for each respondent in any potential setting. We explain this approach by first reviewing the methodology required by the TCM and DCE studies, with a particular focus on econometric derivation of individual-specific values of travel time savings. We then move to an empirical illustration of our approach, which is compared with traditional treatments of value of travel time savings. Our case study not only serves as an example of the methodology we propose, but also illustrates that the usual approach of assuming that respondents' values of travel time savings are proportional to their wages is largely unfounded. The last section offers discussion of the results and conclusions. 


\section{Methods and Econometric Treatment}

\subsection{The Travel Cost Method}

The individual travel cost method treats trips to a site as the quantity demanded, while the cost of the trip as the price of access to the site. These assumptions result in a demand function of the following form:

$$
r_{i}=f\left(p_{i}, \mathbf{z}_{i}\right),
$$

where $r_{i}$ is the number of trips taken by individual $i$ to a given site during a given time period, $p_{i}$ is the cost of access to the site (which usually consists of the cost of travel and opportunity cost of travel time), and $\mathbf{z}_{i}$ is a vector of individual characteristics that are believed to influence the number of trips an individual takes.

In this setting, the consumer surplus associated with accessing the site by an individual $i$ is represented by:

$$
C S_{i}=\int_{p_{i}^{0}}^{p_{i}} f\left(p_{i}, \mathbf{z}_{i}\right) d p_{i}
$$

where $p_{i}^{0}$ is the current trip cost to the site and $p_{i}$ is the cost level at which the number of trips goes to zero, also called individual $i$ 's 'choke price'.

A standard practice is to model single-site recreation demand functions using count data distributions. The two most frequently used count models are Poisson and Negative Binomial. These models are flexible enough to handle truncation, a large number of zero trips in the data, and preference heterogeneity. The main advantage of the Poisson model is that it is a member of the linear exponential family and so its parameters are unbiased as long as the underlying demand relationship is linear exponential. However, the Poisson distribution has the property of equi-dispersion - the first two moments of a distribution are equal, i.e., $E(Y)=\mu=V(Y)$. If a particular data set does not satisfy this assumption, as is in the case of our study, then more efficient estimates of the parameters can be obtained from the negative binomial distribution as it does not require equi-dispersion.

A second area of consideration is the method used to sample the trip data. If the data was sampled on-site the frequency of visitation by a user affects the likelihood of being in the sample. This sampling bias is referred to as endogenous stratification. The more frequently one visits a site the more likely they are to be sampled. A second issue is that only visitors can possibly be sampled. As a result, the sample is also truncated at zero. The problem of endogenous stratification and truncation in the context of travel cost modeling has been addressed for the Poisson model by Shaw (1988). Englin and Shonkwiler (1995) extended the analysis to the truncated and endogenously stratified negative binomial model. Englin and Shonkwiler (1995) accommodated three features of on-site samples concerning count data: over-dispersion, truncation at zero, and endogenous stratification due to oversampling of frequent users of the site. In this model, the probability of individual $i$ making $y_{i}$ trips to the site is given by:

$$
\operatorname{Pr}\left(y_{i} \mid y_{i}>0\right)=y_{i} \frac{\Gamma\left(y_{i}+\alpha_{i}^{-1}\right)}{\Gamma\left(y_{i}+1\right) \Gamma\left(\alpha_{i}^{-1}\right)} \alpha_{i}^{y_{i}} \lambda_{i}^{y_{i}-1}\left(1+\alpha_{i} \lambda_{i}\right)^{-\left(y_{i}+\alpha_{i}^{-1}\right)}, \mathrm{y}_{i}=1,2, \ldots,
$$


where $\Gamma$ represents the gamma function, $\lambda_{i}$ is the mean, which is typically modeled as a function of explanatory variables and $\alpha_{i}$ is the over-dispersion parameter. ${ }^{2}$

\subsection{Discrete Choice Experiments}

In environmental economics stated preference methods are commonly used for modeling consumers' preferences and valuation (Carson and Czajkowski 2014). Respondents' choices are typically modeled in a random utility framework, which assumes that the utility associated with any choice alternative can be divided into a sum of contributions that can be observed by a researcher, and a component that cannot, hence is assumed random. Specifically, consider the following empirical specification of a random utility multinomial choice model:

$$
U_{i}(\text { Alternative }=j)=U_{i j}=\boldsymbol{\beta}_{i}{ }_{i} \mathbf{x}_{i j}+\varepsilon_{i j} \text {, }
$$

where $U_{i j}$ represents respondent $i$ 's utility associated with selecting alternative $j$ out of a set of $J$ available alternatives, $\mathbf{x}_{i j}$ is a vector of respondent- and alternative-specific choice attributes, i.e., goods or their characteristics, and $\boldsymbol{\beta}_{i}$ represents a vector of individual-specific taste parameters associated with marginal utilities of the choice attributes. Assumptions regarding parametric distributions of the taste parameters, such that $\boldsymbol{\beta}_{i} \sim \mathbf{f}(\mathbf{b}, \mathbf{\Sigma})$, where $\mathbf{b}$ is a vector of sample means and $\boldsymbol{\Sigma}$ is a variance-covariance matrix, allows to account for unobserved preference heterogeneity and possibly-correlations between random taste parameters.

The stochastic component of the utility function $(\varepsilon)$ may be interpreted as resulting from researcher's inability to observe all attributes of choice and all significant characteristics of respondents (McFadden 1976), or as decision maker's choice from a set of his decision rules. Random utility theory is transformed into different econometric models by making assumptions about the distribution of the random error term and the random parameters. Typically, $\varepsilon_{i j}$ is assumed to be independently and identically (iid) Extreme Value Type 1 distributed across individuals and alternatives. When unobserved preference heterogeneity is allowed in a way presented above, this leads to a Random Parameters Mixed Logit (RPMXL) model (McFadden and Train 2000).

In what follows, we utilize Bayesian framework for estimating a RP-MXL model and deriving individual-level taste parameters and, as a result, individual-specific VTTS. The advantages of Bayesian approach over classical estimation include easier identification of a global maximum of the likelihood function, and handling correlated random parameters (Huber and Train 2001). In addition, in a Bayesian approach identification of individuallevel parameters is less of an issue than in classical approach, since in extreme cases the prior can provide the necessary information.

Bayesian estimation procedures for the RP-MXL model do not require simulating choice probabilities. Instead, the likelihood of observing individual $i$ making a sequence of $T$ choices $\mathbf{Y}_{i}=\left\{y_{i 1}, \ldots, y_{i t}, \ldots y_{i T}\right\}$ is the product of standard logit formulas, conditional on $\boldsymbol{\beta}$ :

\footnotetext{
2 Amoako-Tuffour and Martínez-Espiñeira (2012) took this reasoning further and allowed the over-dispersion parameter $\alpha_{i}$ to vary according to respondent characteristics (and they used their survey data to indicate which fraction of the wage rate best represented the respondents' opportunity cost of travel time, making also this parameter a function of the respondents' characteristics).
} 


$$
L\left(\mathbf{Y}_{\mathbf{i}} \mid \boldsymbol{\beta}_{i}\right)=\prod_{t=1}^{T_{i}} \frac{\exp \left(\boldsymbol{\beta}_{i}^{\prime} \mathbf{x}_{i y_{i t} t}\right)}{\sum_{j=1} \exp \left(\boldsymbol{\beta}_{i}^{\prime} \mathbf{x}_{i j t}\right)} .
$$

The unconditional probability is the integral of (9) with respect to all values of $\boldsymbol{\beta}_{i}$, weighted by their multivariate probability density $\psi\left(\boldsymbol{\beta}_{i}\right)$ :

$$
P\left(\mathbf{Y}_{i} \mid \mathbf{b}, \mathbf{\Sigma}\right)=\int L\left(\mathbf{Y}_{i} \mid \boldsymbol{\beta}_{i}\right) \psi\left(\boldsymbol{\beta}_{i} \mid \mathbf{b}, \boldsymbol{\Sigma}\right) d \boldsymbol{\beta}_{i}
$$

The Bayesian approach requires specifying priors for the model parameters $\mathbf{b}, \boldsymbol{\Sigma}$ and $\boldsymbol{\beta}_{i}$ for all

$i=1 . . N$. Typically, a diffuse normal distribution (with zero means and diagonal matrix of arbitrarily large variances $\boldsymbol{\Theta}$, allowing for almost flat distribution) is used as a prior for $\mathbf{b}$, $\mathbf{b} \sim M V N(0, \boldsymbol{\Theta})$, and inverted Wishart distribution (with the number of degrees of freedom $K$ equal to the length of $\mathbf{b}$, and parameter $K \mathbf{I}$, where $\mathbf{I}$ is a $K$-dimensional identity matrix) is used as a prior for $\boldsymbol{\Sigma}, \boldsymbol{\Sigma} \sim I W(K, K \mathbf{I})$. The priors for each individual's taste parameters $\boldsymbol{\beta}_{i}$ are proportional to the assumed (population-level) distributions of taste parameters times the priors on $\mathbf{b}$ and $\boldsymbol{\Sigma}$; as an aside, because of this hierarchy of parameters this procedure is often referred to as hierarchical Bayes. As a result, denoting choice sequences of all individuals at all choice occasions as $\mathbf{Y}$, the joint posterior distribution on $\mathbf{b}, \boldsymbol{\Sigma}$ and each $\boldsymbol{\beta}_{i}$ is:

$$
\Lambda\left(\boldsymbol{\beta}_{i} \text { for all } i=1 . . N, \mathbf{b}, \mathbf{\Sigma} \mid \mathbf{Y}\right) \propto \prod_{i=1}^{N} L\left(\mathbf{Y}_{i} \mid \boldsymbol{\beta}_{i}\right) \psi\left(\boldsymbol{\beta}_{i} \mid \mathbf{b}, \boldsymbol{\Sigma}\right) N(\mathbf{b} \mid 0, \boldsymbol{\Theta}) I W(\boldsymbol{\Sigma} \mid K, K \mathbf{I})
$$

Since using the parametric distributions which impose bounds on taste parameters may make direct drawing from the joint posterior distribution difficult, some variant of Metropolis-Hasting algorithm is usually used (Train 2009). ${ }^{3}$

The approach that we propose in this paper extends the traditional TCM by utilizing individual-specific VTTS. In order to make this possible and, at the same time, allow for preference heterogeneity it is crucial to obtain individual-level taste parameter estimates. Although in this paper we adopt a Bayesian approach, Huber and Train (2001) showed that reliable individual-level parameters for discrete choice models can be obtained irrespectively of the estimation or inference framework. Within a Bayesian framework, the distribution of coefficients across the population is estimated and used as a prior, which combined with individual's choices results in posterior estimates of each individual's tastes (Rossi et al. 1996; Allenby and Rossi 1998). Similarly, in a classical setting, applying Bayes theorem, i.e., combining maximum likelihood estimates of the population distribution with individual choices, makes derivation of individual-specific parameter estimates possible (Revelt and Train 2000). Huber and Train (2001) showed that these approaches lead to largely equivalent results.

\section{Empirical Study}

In order to investigate differences resulting from applying individual-level estimates of travel time versus the traditionally assumed value of time we designed and implemented a joint TCM-DCE study in the context of recreational birdwatching.

\footnotetext{
3 Interestingly, the results of the estimation procedure are asymptotically equivalent to the classical, maximum likelihood estimator. The results can thus be given a dual—classical and Bayesian-interpretation.
} 


\subsection{Study Site, Experimental Design and Survey Administration}

The study site selected for this application was Żywkowo, one of Polish 'stork villages'-a term used by a recent New York Times article about them (Whitaker 2015). A stork village is a common name for a village with a white stork (Ciconia ciconia) breeding colony, often inhabited by more storks than people. Żywkowo, the best-known stork village in Poland, has approximately 40 white stork nests and 10 households, while it receives approximately 2000-5000 tourists annually, many of whom come from abroad. Żywkowo lays in the north-east of Poland, on the periphery of one of the most attractive parts of the country to tourists, the Masurian Lake District. It is not located near any major tourist attraction and is relatively far from larger cities; in addition, since there are no other attractions in the village it is visited solely because of birds, and more specifically-because of white storks.

The questionnaire was designed to collect the usual data necessary for a TCM study. We asked where the tourists came from, distinguishing between their most recent stop (if they visited more than one place during their trips) and their place of residence. We also asked how long the travel took, what means of transportation were used and the number of people travelling in a party. In order to identify respondents who, in general, had positive willingness to pay for travel time savings we asked if they had wished their travel time to the site was shorter. ${ }^{4}$ After that, respondents who expressed general interest in making their travel time shorter were asked to participate in hypothetical discrete choice tasks designed to reveal their WTP for travel time savings. Finally, respondents were asked socio-economic questions, providing information about their age, gender, income, level of education, and basic birdwatching preferences. Questionnaires were available in Polish, German and English. ${ }^{5}$

The DCE part of the survey was introduced as follows:

Now we would like to ask you to take part in an exercise that involves making some choices. Imagine that the trip from the last place of your stay could be shorter. However, it would require an additional cost. You would have to personally pay this cost and it would increase the current cost of your trip. Please assume that shortening the trip would not decrease the costs of your travel. You could spend the time that you would save in any preferred way, for example resting or working.

In a moment you we will show you several hypothetical situations that present different combinations of time saved and the related cost. In each case, please choose a variant that you consider the best - from your own point of view (please think about yourself only).

Bear in mind that the additional cost would reduce your budget available for other purposes. This is why we ask you to treat this cost as if you would really have to pay it. If you would not be willing to pay anything extra for the saved time, choose Alternative 1 - status quo.

The DCE utilized up to 6 choice tasks per respondent. Each choice task consisted of 3 alternatives - one status quo alternative associated with no travel time savings and no

\footnotetext{
4 The exact wording of the question was: "Would you prefer the trip from the last place of your last stay to be shorter? (a) Yes; (b) No; (c) I do not know". Respondents who answered (a) or (c) were considered to be 'in the market' for shortening their journey time.

5 More details about the survey are available in Czajkowski et al. (2014).
} 
Table 1 The attribute levels as used in the DCE questions

\begin{tabular}{lll}
\hline & Time reduction & Cost \\
\hline Trips $<1 \mathrm{~h}$ & $10,20,30 \mathrm{~min}$ & $5,10,15 \mathrm{PLN}^{\mathrm{a}}$ \\
Trips $1-3 \mathrm{~h}$ & $30,60,90 \mathrm{~min}$ & $10,20,30 \mathrm{PLN}$ \\
Trips $>3 \mathrm{~h}$ & $60,90,120 \mathrm{~min}$ & $20,30,40 \mathrm{PLN}$ \\
Self-administered & $25 \%, 50 \%$ & $5,10,20,50 \mathrm{PLN}$ \\
$\quad$ surveys & & \\
\hline
\end{tabular}

${ }^{\mathrm{a}} 1 \mathrm{PLN} \approx 0.25 \mathrm{EUR} \approx 0.33 \mathrm{USD}$

costs, and two alternatives associated with different travel time savings and additional cost. There were 3 versions of the DCE questions which differed in the utilized attribute levels, depending on respondent's travel time and an additional version for self-administered surveys that used relative travel time reduction levels. The attribute levels are presented in Table 1.

The design of each DCE version was generated using NGENE. We optimized each experimental design for the D-efficiency of an MNL model using Bayesian priors (Ferrini and Scarpa 2007). All prior estimates were assumed to be normally distributed, with their means derived from the MNL model estimated on the dataset from the pilot survey, and standard deviations equal to 0.25 of each parameter's mean (with an absolute minimum for means that were very close to zero). Additionally, the design included constraints on attribute level combinations, to rule out dominated or repetitive alternatives.

Tourists visiting Żywkowo were surveyed on site between April and September of 2011, that is, since when the storks returned from their spring migration to when they left for autumn migration. Questionnaires were available to tourists visiting an exhibition room. Tourists were prompted to take part in the study by local employees and, additionally, by interviewers who assisted the local staff at times when the tourists were the most numerous. In 2011, 2850 tourists visited the exhibition room, of whom 583 agreed to complete the questionnaire, resulting in a response rate above $20 \%{ }^{6}$ Socio-demographic characteristics of the sample and main descriptive statistics of the journeys are presented in Table 2.

\subsection{Deriving Respondent-Specific Values of Travel Time Savings with Discrete Choice Experiment Approach}

We start by presenting the results of the discrete choice experiment estimated for respondents who indicated that they wished their journey to the study site had been shorter ( $n=247,47 \%$ ). Respondents who answered 'No' were assumed not to be 'in the market' for shortening their journey, and hence their WTP for travel time savings was $0 .^{7}$

\footnotetext{
${ }^{6}$ We are unable to compare the sample characteristics with the characteristics of the target population because the characteristics of the target population (visitors of the study site) are unavailable. However, we note that share of surveyed visitors was relatively large, the interviews were collected throughout the entire season and the respondents were selected randomly from the visitors available at a time (for parties traveling together, only respondents who actually paid for the trip were surveyed; in the case of more than one person paying for the trip (e.g., a family with joint budget or a party who shared costs) — the respondent was selected randomly).

7 This is consistent with early theoretical contributions to microeconomic time allocation theory and travel time valuation, which recognized that, in some cases, travel may be enjoyable (e.g., Becker 1965; Johnson 1966; Evans 1972). Another line of research related to why people do not want their trip to be shorter is related to non-shortest-path route choice. There is now numerous evidence of this type behavior (Agrawal et al. 2008; Bovy and Stern 2012; Broach et al. 2012). These studies evidence that people do not always choose the shortest, fastest, or cheapest route to their destination. It is well recognized in the transportation
} 
Table 2 Descriptive statistics of the sample

\begin{tabular}{|c|c|c|c|}
\hline & Mean/share & Median & SD \\
\hline Distance travelled & 119.78 & 77 & 194.91 \\
\hline Travel time (h) & 2.10 & 1.50 & 2.41 \\
\hline \multicolumn{4}{|l|}{ Principal means of transportation used to reach the study site } \\
\hline Car or motorcycle & $83.99 \%$ & & \\
\hline Train & $0.69 \%$ & & \\
\hline Bus & $13.25 \%$ & & \\
\hline On foot or by bicycle & $1.03 \%$ & & \\
\hline Other & $0.51 \%$ & & \\
\hline Travelling with others & $94.49 \%$ & & \\
\hline Age & 44.62 & 43.00 & 15.00 \\
\hline \multicolumn{4}{|l|}{ Education } \\
\hline Primary & $5.11 \%$ & & \\
\hline Secondary & $36.68 \%$ & & \\
\hline Tertiary & $58.20 \%$ & & \\
\hline \multicolumn{4}{|l|}{ Net household income } \\
\hline Less than 2000 PLN & $12.53 \%$ & & \\
\hline 2000-2499 PLN & $12.53 \%$ & & \\
\hline 2500-3499 PLN & $17.83 \%$ & & \\
\hline 3500-4499 PLN & $13.25 \%$ & & \\
\hline 4500-9000 PLN & $21.20 \%$ & & \\
\hline Over 9000 PLN & $10.12 \%$ & & \\
\hline No response & $12.53 \%$ & & \\
\hline \multicolumn{4}{|l|}{ Net household income level (German or British) $(n=166)$} \\
\hline Less than 2000 EUR & $8.43 \%$ & & \\
\hline 2000-2499 EUR & $13.25 \%$ & & \\
\hline 2500-3499 EUR & $12.65 \%$ & & \\
\hline 3500-4499 EUR & $11.45 \%$ & & \\
\hline 4500-9000 EUR & $12.05 \%$ & & \\
\hline Over 9000 EUR & $4.82 \%$ & & \\
\hline No response & $37.35 \%$ & & \\
\hline Household size & 3.01 & 3.00 & 1.20 \\
\hline \multicolumn{4}{|l|}{ How often does a respondent travel to watch birds? } \\
\hline Never/very rarely & $58.99 \%$ & & \\
\hline Sometimes & $33.68 \%$ & & \\
\hline Regularly_because of work (e.g., research, professional photography) & $5.24 \%$ & & \\
\hline Regularly_and not related to work & $2.09 \%$ & & \\
\hline
\end{tabular}

Footnote 7 (continued)

literature that positive utility of travel may be at play, if travelers want to travel farther than necessary or if they choose more scenic or enjoyable but out-of-the way paths. 
Table 3 The results of the discrete choice model

\begin{tabular}{llll}
\hline & Multinomial logit & Mixed logit & \\
\cline { 3 - 4 } & Taste parameters & $\begin{array}{l}\text { Means of random taste } \\
\text { parameters }\end{array}$ & $\begin{array}{l}\text { Standard deviations of } \\
\text { random taste param- } \\
\text { eters }\end{array}$ \\
\hline Status quo (alternative & $0.5971 * * *$ & -1.1509 & $6.2097 * * *$ \\
specific constant) & $(0.0931)$ & $(0.9722)$ & $(1.4739)$ \\
Travel time savings & $0.1682^{* * *}$ & -0.2565 & $0.7168 * *$ \\
Cost & $(0.0562)$ & $(0.3189)$ & $(0.2964)$ \\
& $0.0077 *$ & $-2.6623 * * *$ & $2.0035 * *$ \\
& $(0.0040)$ & $(0.3797)$ & $(0.9720)$ \\
\hline Simulated log-likelihood & & Model diagnostics & \\
AIC/n & & -1312.7 & -889.67 \\
BIC/n & & 2.1085 & 1.4354 \\
$n$ (observations) & & 2.1208 & 1.4600 \\
$r$ (respondents) & & 1248 & 1248 \\
(parameters) & & 247 & 247 \\
\hline
\end{tabular}

$*, * *, * * *$ indicate significance at $10 \%, 5 \%$, and $1 \%$ level, respectively. Standard deviations/standard errors given in parentheses. For log-normally distributed parameters (Travel time savings, -Cost), the estimates of the parameters of the underlying normal distribution are provided

The RP-MXL model was estimated using the Bayesian procedures described in Sect. 2.2. The choice attributes included travel time savings, cost and an alternative specific constant associated with the status quo alternative. All taste parameters were assumed random. Since economic theory indicates that utility associated with (negative) cost and travel time savings (for respondents who indicated that they wished their journey had been shorter) cannot be negative, we assumed that population-level parameters of these attributes were log-normally distributed. The parameter of the alternative specific constant for the status quo alternative was assumed to follow normal distribution.

The estimation was performed in Matlab. ${ }^{8}$ In our application, we used $10^{5}$ iterations for 'burn-in' (the iterations used by Metropolis-Hasting algorithm within which the draws converge to the target, conditional posterior distribution), and after that we retained every 11 th iteration result for the total of $10^{5}$ iterations used to conduct inference, i.e., from a classical perspective, deriving estimates of the parameters. ${ }^{9}$ Finally, we used $10^{6}$ draws per individual to simulate the estimated distributions of random parameters and to calculate simulated log-likelihood value. The step length for the Metropolis-Hasting algorithm was set to 0.3 , well within the range suggested by Gelman et al. (2003).

The estimation results are presented in Table 3. The first column represents the reference MNL model. The improvement in model fit from the MNL to the RP-MXL model with correlated parameters, as indicated by Akaike information criterion (AIC) and Bayesian information criterion (BIC), is an evidence of substantial heterogeneity in respondents'

\footnotetext{
8 The dataset and software codes for the models used in this paper are available from http://czaj.org/resea rch/supplementary-materials.

${ }^{9}$ We retained only every 11 th draw in order to reduce the amount of correlation among the draws.
} 
Table 4 Descriptive statistics of respondent-specific values of travel time savings and wage rates (PLN/h)

\begin{tabular}{|c|c|c|c|c|}
\hline & \multicolumn{2}{|c|}{ Value of travel time savings } & \multicolumn{2}{|l|}{ Wage rate } \\
\hline & All respondents & $\begin{array}{l}\text { Respondents who wished } \\
\text { their journey was shorter }\end{array}$ & All respondents & $\begin{array}{l}\text { Respondents who wished } \\
\text { their journey was shorter }\end{array}$ \\
\hline Mean & 6.36 & 11.99 & 13.03 & 12.30 \\
\hline Median & 0.04 & 7.49 & 9.38 & 9.38 \\
\hline SD & 13.18 & 16.14 & 8.89 & 8.68 \\
\hline 0.025 quantile & 0.00 & 0.03 & 2.13 & 2.08 \\
\hline 0.975 quantile & 40.97 & 52.52 & 28.13 & 28.13 \\
\hline
\end{tabular}

preferences. This is confirmed by relatively large estimates of standard deviations of population parameters. The results of a likelihood ratio tests show that indeed, all parameters should be modeled as random.

The estimation results presented above allowed us to derive individual-specific parameters in a fashion described in Sect. 2.2. These parameters were in turn used to simulate ${ }^{10}$ individual-level willingness to pay for travel time savings, following Small and Rosen (1981) and Hanemann (1984):

$$
C V=\frac{1}{\mu}\left\{\ln \sum_{1}^{n} \exp \left(\boldsymbol{\beta}^{\prime} \mathbf{x}_{0}\right)-\ln \sum_{1}^{n} \exp \left(\boldsymbol{\beta}^{\prime} \mathbf{x}_{1}\right)\right\}
$$

where $\mu$ is the marginal utility of income (the parameter on price), $\boldsymbol{\beta}$ is vector of estimated parameters of the indirect utility function, $\mathbf{x}_{0}$ are the levels of the attributes in the reference situation and $\mathbf{x}_{1}$ are the levels of the attributes in the improved situation. In our case, we assumed two alternatives ( $n=2$; status quo and non-status quo) and the improvement in the form of 1-h travel time reduction, which occurred in the non-status quo alternative of $\mathbf{x}_{1}$.

Descriptive statistics of these individual-specific values of travel time savings for the sample of our respondents are presented in Table 4. For comparison, the table also includes the statistics for respondents' wage rates. ${ }^{11}$

The results of this exercise allow for a few interesting conclusions. First of all, even a relatively simple discrete choice experiment can allow for calculating respondent-specific values of travel time savings. The descriptive statistics presented in Table 4 show that individual-specific values of WTP for travel time savings are plausible for virtually all respondents in our sample.

\footnotetext{
10 Only respondents who declared that they wished their journey was shorter were included in this analysis; the others were assumed not to be willing to pay for travel time savings (VTTS $=0$ ). In simulation we accounted for effective means of the distributions which were modelled as truncated normal.

11 The wage rate was calculated as net (after tax) household income (including all sources of income, such as salaries, pensions, rents etc.) divided by the number of adults in a household and divided by 160 (regular number of working hours per month). While this is not strictly the individual's wage per hour, it represents the family budget constraint, which is often the more appropriate measure of purchasing decisions (Lindhjem and Navrud 2009). For respondents who refused to disclose their household income, we arbitrarily assumed their income was equal to the sample mean.
} 


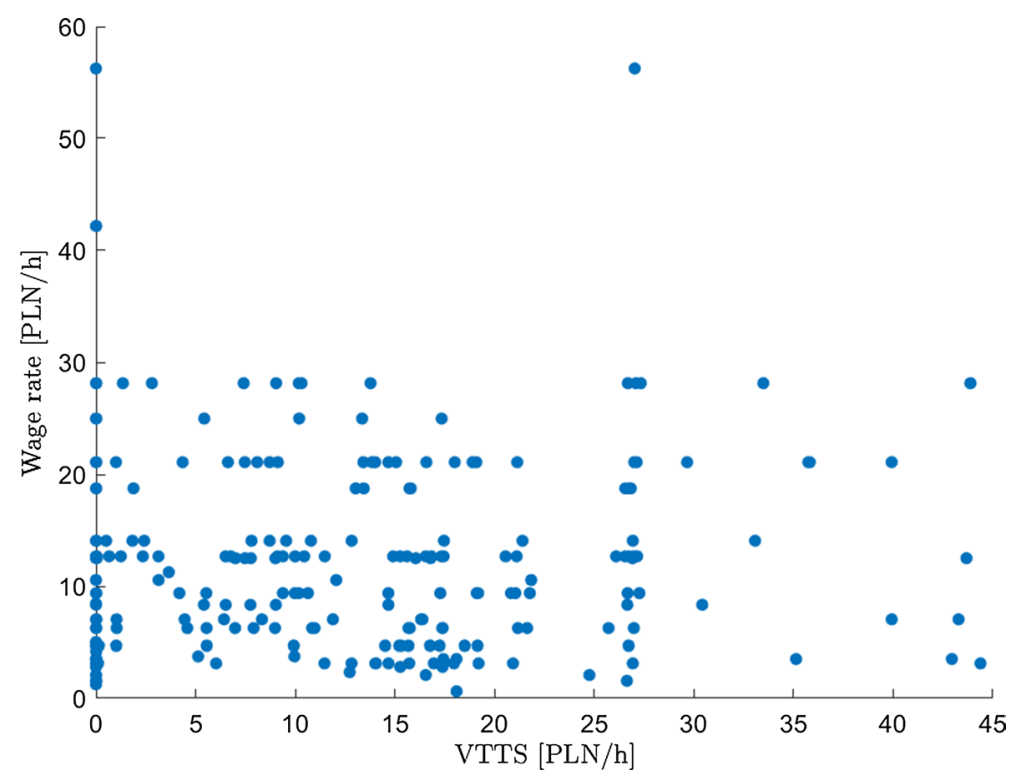

Fig. 1 Respondents' wage rates and implied values of travel time savings

Secondly, we find that all respondents' mean value of 1-h travel time savings is very close $1 / 2$ of their mean wage rate. However, on closer inspection, $47 \%$ of respondents declared that they did not wish their journey was shorter, implying VTTS $=0$. In addition, $29.81 \%$ of those who were generally 'in the market' for shortening their travel times still made choices which implied very low VTTS (e.g., did not choose the costly improvement alternative in any of the choice tasks). ${ }^{12}$ Interestingly, mean VTTS of those who indicated they wished their journey was shorter is close to their (full) mean wage rate. Finally, we note that the correlation of respondents' VTTS and their wage rate is very low $(0.0411$ for all respondents, 0.1191 for those who declared they wished their journey was shorter).

We investigate the relationship between respondents' VTTS and wage rate further using graphical illustration provided in Fig. 1. If VTTS and wage rates were correlated, we would expect a positive linear relationship. Instead, we find that respondents' WTP for shortening their trip is largely independent of their wage rate.

Overall, our results do not support using respondents' wage rate as a proxy for their VTTS. Instead, we argue for utilizing stated preference methods for measuring individual level VTTS and in what follows, we demonstrate substantial differences resulting from utilizing individual-level versus aggregated versus traditional assumptions regarding the value of travel time in travel cost models.

\footnotetext{
12 As noted by one of the reviewers, this is a likely indication of a status quo bias that may have implications for our estimated consumer surplus indicators.
} 
Table 5 The analysis of respondents' heterogeneity with respect to VTTS

\begin{tabular}{|c|c|c|}
\hline & $\begin{array}{l}\text { Probit model for respondents' willingness to } \\
\text { shorten their journey }\end{array}$ & $\begin{array}{l}\text { Linear regression } \\
\text { model of respondents } \\
\text { VTTS }\end{array}$ \\
\hline Constant & $\begin{array}{l}-2.4393 * * * \\
(0.4939)\end{array}$ & $\begin{array}{l}-6.0493 \\
(4.1562)\end{array}$ \\
\hline Travel time & $\begin{array}{l}0.3138 \text { *** } \\
(0.0821)\end{array}$ & $\begin{array}{l}3.6811 \text { *** } \\
(0.7996)\end{array}$ \\
\hline Travel time ${ }^{2}$ & $\begin{array}{l}-0.0161^{*} \\
(0.0084)\end{array}$ & $\begin{array}{l}-0.2664 * * * \\
(0.0827)\end{array}$ \\
\hline Household size & $\begin{array}{l}0.1570 * * \\
(0.0723)\end{array}$ & $\begin{array}{l}1.9403 * * * \\
(0.6870)\end{array}$ \\
\hline Number of children & $\begin{array}{l}-0.1051 \\
(0.0998)\end{array}$ & $\begin{array}{l}-2.8328 * * * \\
(0.9381)\end{array}$ \\
\hline Age & $\begin{array}{r}0.0040 \\
(0.0048)\end{array}$ & $\begin{array}{l}-0.0576 \\
(0.0448)\end{array}$ \\
\hline Male & $\begin{array}{r}0.1374 \\
(0.1325)\end{array}$ & $\begin{array}{r}0.2518 \\
(1.2655)\end{array}$ \\
\hline Education-medium & $\begin{array}{l}0.6720^{*} \\
(0.3489)\end{array}$ & $\begin{array}{r}3.0480 \\
(2.8149)\end{array}$ \\
\hline Education-high & $\begin{array}{l}0.8495^{* * *} \\
(0.3523)\end{array}$ & $\begin{array}{r}3.9223 \\
(2.8664)\end{array}$ \\
\hline Wage rate & $\begin{array}{l}-0.0012 \\
(0.0085)\end{array}$ & $\begin{array}{c}0.1465^{*} \\
(0.0798)\end{array}$ \\
\hline
\end{tabular}

$*, * *, * * *$ indicate significance at $10 \%, 5 \%$, and $1 \%$ level, respectively. Standard errors given in parentheses. The models were estimated using data from 452 respondents (respondents with missing data were omitted)

\subsubsection{Individual Heterogeneity with Respect to VTTS}

In order to provide an insight into respondents' heterogeneity with respect to their VTTS we present the logit model for 'market participation'-respondents' answers to the question if they (in general) would prefer that their journey was shorter and a simple linear regression model in which individual-specific VTTS are explained with respondents' socio-demographic variables (Table 5).

The results show that respondents whose journeys were longer were more likely to answer that they indeed wished their journey had been shorter; the relationship is convex, as indicated by the negative coefficient associated with the travel time squared. ${ }^{13}$ These results coincide with individual specific VTTS - respondents who had to travel longer were willing to pay more to shorten their journey (although at a decreasing rate). Additionally, we find that respondents with medium or high level of education are more likely to state that they wish their journey was shorter. Respondents from larger households are also statistically willing to pay more for travel time reduction, although this last effect is

\footnotetext{
13 This result is consistent with the transportation literature findings that the satisfaction with the travel experience and travel liking tends to decrease with longer trip distances or durations (Rasouli and Timmermans 2014; Milakis et al. 2015; Morris and Guerra 2015) (e.g., Rasouli and Timmermans 2014; Milakis et al. 2015; Morris and Guerra 2015).
} 
Table 6 Respondents' travel costs under different assumptions with respect to VTTS (PLN)

\begin{tabular}{lrcccc}
\hline $\begin{array}{l}\text { Respondents' } \\
\text { travel cost when }\end{array}$ & $V_{T T S_{i}=0}$ & $\begin{array}{l}\text { VTTS } \\
\text { wage rate }\end{array}$ & $\begin{array}{l}\text { VTTS } \\
\text { wage rate }\end{array}$ & $\begin{array}{l}\text { VTTS derived from } \\
\text { the MNL model }\end{array}$ & $\begin{array}{l}\text { VTTS derived from } \\
\text { the RP-MXL model }\end{array}$ \\
\hline Mean & 23.54 & 28.83 & 39.41 & 31.41 & 39.82 \\
Median & 15.40 & 16.00 & 20.69 & 16.20 & 16.00 \\
SD & 33.71 & 40.21 & 56.63 & 44.17 & 73.99 \\
0.025 quantile & 2.60 & 2.60 & 2.60 & 2.60 & 2.60 \\
0.975 quantile & 137.15 & 180.55 & 222.48 & 184.24 & 282.01 \\
\hline
\end{tabular}

counterfeited for respondents with children. Finally, we note that once respondents' sociodemographic characteristics are controlled for, their wage was not a significant explanatory variable of willing to shorten one's journey, ${ }^{14}$ and only weakly significant for explaining their individual VTTS. This is in stark contrast with the common practice of utilizing fraction of one's income as a proxy for their VTTS (Parsons 2017).

These results have profound implications. Since respondents whose traveling times are larger have higher WTP for shortening their journey it clearly follows that using mean VTTS for every respondent in the sample will negatively bias the cost of travel time. This is because observations with higher individual-specific VTTS have higher weights in the utility function (more hours multiplied with higher cost per hour). In addition, since respondents' VTTS appears statistically independent from their wage, using individualspecific wage rates as a proxy of VTTS is not convincing approach either. We illustrate this finding with the comparison of different modeling approaches in the next section.

\subsection{Travel Cost Method with Consumer-Specific Values of Travel Time Savings}

In this section we present the estimation results of 5 travel cost models with different assumptions with respect to respondents' VTTS. Generally, visitor $i$ 's expected number of trips can be calculated as:

$$
\lambda_{i}=\exp \left(\beta_{T C} T C_{i}+\boldsymbol{\beta}^{\prime} \mathbf{Z}_{i}\right)
$$

which serves as our travel cost recreation demand function. The $T C_{i}$ represents individual $i$ 's cost associated with reaching the stork village and $\mathbf{Z}_{i}$ is a vector of individual characteristics that are considered to influence the number of trips $i$ takes (in our case, since we intended to keep our approach as simple as possible, we only used a constant).

The average cost of traveling $1 \mathrm{~km}$ was assumed to be $0.45 \mathrm{PLN}^{15}$; however, when calculating cost per person we took a travelling party size into account. As far as the VTTS is concerned, the following alternative specifications were used:

(1) $\mathrm{VTTS}=0$;

(2) $\operatorname{VTTS}=1 / 3$ of respondent's wage rate;

(3) VTTS = respondent's wage rate;

\footnotetext{
14 Wage remains insignificant even if (possibly correlated) education is not included as an explanatory variable, and if it is the only explanatory variable in the model.

15 We used the official average operating cost according to the Polish Automobile Association. This rate is commonly used for reimbursing employees who use private vehicles for official business.
} 
Table 7 The TCM models estimation results

\begin{tabular}{|c|c|c|c|c|c|}
\hline & $\begin{array}{l}\text { Model } 1 \\
\left(V T T S_{i}=0\right)\end{array}$ & $\begin{array}{l}\text { Model } 2 \\
\left(\operatorname{VTTS}_{i}=1 / 3\right. \\
\text { wage rate })\end{array}$ & $\begin{array}{l}\text { Model } 3 \\
\left(V T T S_{i}=\text { full }\right. \\
\text { wage rate })\end{array}$ & $\begin{array}{l}\text { Model } 4\left(V T T S_{i}\right. \\
\text { derived from the } \\
\text { MNL model) }\end{array}$ & $\begin{array}{l}\text { Model } 5 \text { (VTTS } \\
\text { derived from the } \\
\text { RP-MXL model) }\end{array}$ \\
\hline$\beta_{\text {constant }}$ & $\begin{array}{l}-5.4283^{* * *} \\
(1.0258)\end{array}$ & $\begin{array}{l}-5.4125 * * * \\
(1.0306)\end{array}$ & $\begin{array}{l}-5.4125^{* * * *} \\
(1.0239)\end{array}$ & $\begin{array}{l}-5.4361 * * * \\
(1.0262)\end{array}$ & $\begin{array}{l}-5.4966^{* * * *} \\
(1.0204)\end{array}$ \\
\hline$\beta_{T C_{i}}{ }^{\mathrm{a}}$ & $\begin{array}{l}-6.0200^{* * * *} \\
(1.7377)\end{array}$ & $\begin{array}{l}-5.4185^{* * * *} \\
(1.5142)\end{array}$ & $\begin{array}{l}-3.9599 * * * \\
(1.1299)\end{array}$ & $\begin{array}{l}-4.4318^{* * * *} \\
(1.3449)\end{array}$ & $\begin{array}{l}-2.5619 * * * \\
(0.9197)\end{array}$ \\
\hline$\alpha_{i}^{*}$ & $\begin{array}{l}4.5407 * * * \\
(1.0346)\end{array}$ & $\begin{array}{l}4.5456 * * * \\
(1.0394)\end{array}$ & $\begin{array}{l}4.5421 \text { *** } \\
(1.0323)\end{array}$ & $\begin{array}{l}4.5476 * * * \\
(1.0351)\end{array}$ & $\begin{array}{l}4.5406 * * * \\
(1.0295)\end{array}$ \\
\hline
\end{tabular}

$*, * *, * * *$ indicate significance at $10 \%, 5 \%$, and $1 \%$ level, respectively. Standard errors given in parentheses. The models were estimated using data from 583 respondents

${ }^{\mathrm{a}} T C_{i}$ was expressed in $1000 \mathrm{PLN}$

(4) VTTS = mean WTP derived from the MNL model;

(5) VTTS = individual-specific WTP derived from the RP-MXL model.

In all cases, we only included the cost associated with the travel time for respondents who indicated that they wished their journey was shorter. The resulting travel costs, calculated under different assumptions with respect to VTTS, are presented in Table 6.

We estimated the count data models in a Bayesian framework, applying the independence chain Metropolis-Hastings algorithm with a multivariate $t$ distribution (with mean $(\hat{\boldsymbol{\beta}})$ equal to the mode of the posterior kernel, and variance equal inverted negative Hessian resulting from the maximum likelihood estimator subroutine evaluated at $\hat{\boldsymbol{\beta}})^{16}$ as a candidate-generating density (Chib et al. 1998; Davis and Moeltner 2010). The Gibbs Sampler was implemented with 100,000 burn-in draws and 10,000 retained draws. ${ }^{17}$

The estimation results are presented in Table 7. As expected, the travel cost coefficient is negative and statistically significant at the $1 \%$ level in all the models. The constant and

\footnotetext{
16 The tuner elements for these t-distributions were set as the degrees of freedom $=8$ for means and a scalar 2 for the variance. These settings led to desirable acceptance rates and efficiency measures.

17 As an aside, we have also tried to combine the two estimation steps into one. This can theoretically be done by saving the appropriate number of iteration- and individual-specific parameters from the discrete choice part (and hence iteration- and individual-specific VTTS values) and utilizing them for each of the iterations conducted in step 2. In other words, each iteration in the estimation of the count data model would use a different explanatory vector, thus preserving the conditionality that links the two equations. However, this approach turned out to be infeasible, due to some iteration- and individual-specific VTTS being undefined or plus/minus infinity, particularly when the value of the cost parameter was drawn very close to 0 . As a result, the estimation of the count data model could not proceed without additional assumptions (such as assuming that VTTS of such respondents was 0, or sample mean). In addition to the independence chain version of the Metropolis-Hastings algorithm which requires optimizing the LL function (and hence evaluating gradients) for each iteration and causes additional problems if some of the observations are not real numbers, we tried a simpler, random walk version of this algorithm. This approach also turned out infeasible for simultaneous estimation because even without the necessity to calculate gradients the value of the log-likelihood function was often undefined. We acknowledge the statistical inefficiency of a two-step estimation procedure, which is likely to bias the standard errors of the model estimates presented in Table 7.
} 
Table 8 Consumer surplus estimates [PLN]

\begin{tabular}{llllll}
\hline & $\begin{array}{l}\text { Model 1 } \\
\left(V T T S_{i}=0\right)\end{array}$ & $\begin{array}{l}\text { Model 2 } \\
\left(V T T S_{i}=1 / 3\right. \\
\text { wage rate })\end{array}$ & $\begin{array}{l}\text { Model 3 } \\
\left(V T T S_{i}=\text { full }\right. \\
\text { wage rate })\end{array}$ & $\begin{array}{l}\text { Model 4 }\left(V T T S_{i}\right. \\
\text { derived from the } \\
\text { MNL model })\end{array}$ & $\begin{array}{l}\text { Model 5 }\left(V T T S_{i}\right. \\
\text { derived from the } \\
\text { RPsMXL model })\end{array}$ \\
\hline CS & 166.09 & 184.54 & 252.50 & 225.56 & 389.42 \\
$95 \%$ CI & $105.96-380.83$ & $119.14-406.81$ & $161.79-570.75$ & $141.21-552.56$ & $226.72-1249.17$ \\
\hline
\end{tabular}

the over-dispersion parameter $\alpha_{i}$ are also highly significant. ${ }^{18}$ It is impossible to directly compare the models in terms of fit, as each one is essentially estimated on a different dataset, and hence they are not presented in Table 7. A common theme is that the intercept term is relatively stable across specifications ranging from -5.4125 to -5.4966 , virtually indistinguishable from each other statistically. The over-dispersion parameters are also similar. The slope parameters while not statistically different at conventional test levels follow the usual pattern of higher values of time flattening the slope of the estimated demand curve.

We now turn to presenting the welfare measures associated with the different VTTS assumptions made in Models 1 to 5. Consumer surpluses (CS) per person per trip were calculated as an inverse of the estimated travel cost parameter $\left(-1 / \beta_{T C}\right)$. The $95 \%$ confidence intervals were simulated. The results are reported in Table 8.

As the parameter estimates for the demand functions suggest will happen, the welfare estimates for flatter demand curves (ones with higher values for time) are higher. The individual random parameters model provides the highest welfare measures, however, all the CS are plausible (they are in the range of CS reported in other TCM studies conducted in Poland, e.g., Panasiuk 2001; Bartczak et al. 2008; Bartczak et al. 2012; Czajkowski et al. 2015; Kulczyk et al. 2016; Czajkowski et al. 2018; Gawrońska et al. 2018; Wiśniewska et al. 2018).

\section{Discussion and Conclusions}

In this paper we propose to combine the usual TCM data with respondent-specific estimates of the value of travel time savings. Although slightly more complicated and more strenuous for respondents, this approach is much more informative than utilizing values of times derived from respondents' wage rate or stated preference results assuming common value for all individuals in the sample.

Our approach is different from those proposed so far in that we do not just extrapolate the appropriate wage rate based on the respondents' socio-economic data combined with other sources, nor any structural analysis of the value of time for our respondents. Our DCE

\footnotetext{
18 On a technical note, since the candidate parameters for the count data model are derived from a multivariate $\mathrm{t}$ distribution, we found that with sufficiently large variance, every so often the candidate draw for the $\alpha$ parameter was negative. This caused numerical problems, as the gamma function (see Eq. 6) is only defined for positive values. In order to impose this theory-driven constraint we revised Eq. (6) in such a way, that $\alpha=\exp \left(\alpha^{*}\right)$ and optimized for $\alpha^{*}$ (similarly to the method proposed by Carson and Czajkowski 2019). This proved a convenient way to ensure that $\alpha$ has no support for negative values, while not changing the log-likelihood function. Similarly, we found that expanding the logarithm of Eq. (6) in such a way that one uses the log gamma instead of gamma function allows to avoid further numerical problems with exploding values for some iterations.
} 
questions are more flexible than the approach of Fezzi et al. (2014), in that they are general and not specific to our study. At the same time, this approach limits the scope of researcher judgment necessary to estimate the opportunity cost of travel time, and it reduces the need for external data to be combined with survey data in an attempt to calculate the opportunity cost of travel time in a structural way.

In light of the difficulties and ambiguities related to the opportunity cost of travel time, some authors decided not to incorporate time costs in their travel cost models (Hanley et al. 2003; Alberini and Longo 2006; Alberini et al. 2007; Fleming and Cook 2008). ${ }^{19}$ One of the reasons for this approach is the apprehension that incorporating time might bias the coefficient on the price downwards. Another problem might be that time spent in travel might have a value on its own - travelling might be generating utility for some travelers, resulting from enjoying landscapes and amenities, deriving pleasure from a particular means of transportation, adventure-seeking, variety-seeking and be otherwise productively used (Chavas et al. 1989; Lyons and Urry 2005; Mokhtarian 2005; Ory and Mokhtarian 2005). In our study, $47 \%$ of respondents declared that they would wish to reduce the travel time of their journey. These results are consistent with previous studies investigating the value of time spent on leisure journeys, which highlight that sometimes the time spent in travel may be worth more than on the final spot (Anable and Gatersleben 2005; Larson and Lew 2005). Indeed, Żywkowo is located in a remote but particularly picturesque part of the country, with narrow roads lined with large trees, and several other tourist attractions in the region. Clearly, our study helps to challenge the common assumption that "travel is a disutility to be minimized" (Mokhtarian 2005, p. 93).

Our study indicates that it is not necessary nor adequate to use a fraction of hourly earnings because the opportunity cost of time can be measured more accurately by allowing respondents to express their preferences regarding the time they spend in travel. In this way, we move even further with the argument that the opportunity cost of travel time is defined endogenously - it is a function of visitor's characteristics. We explicitly account for the opportunity cost of travel time perceived by respondents, as opposed to the real cost of travel time they may incur (Amoako-Tuffour and Martínez-Espiñeira 2012). Such a flexible approach allows us to account for the fact that travel time is decided by each individual who can choose longer or shorter routes, considering the consumptive value of travel time. The idea that the valuation of travel time is highly subjective was present in the discussion already since Cesario (1976). Indeed, we observed substantial heterogeneity in respondents' preferences in our study, particularly with $47 \%$ of respondents declaring that they would not wish their travel time was shorter, and the VTTS of the other respondents very weakly correlated with their wage rates.

Our study has several limitations and it is important to acknowledge them. First, while the dominant empirical approach to infer VTTS in the transportation literature is based on experiments, in which respondents are asked to make hypothetical choices or personal travel time gains in exchange for travel costs paid from their own budget, this approach is no longer in line with the state-of-the-art stated preference valuation methodology.

\footnotetext{
${ }^{19}$ An alternative to using the opportunity cost of time was proposed by Shrestha et al. (2002) and later applied by Hanley and Barbier (2009). They included travel time in hours as an extra variable, alongside travel cost. The estimated time that respondents would be willing to spend in travel can then be translated into economic value, when combined with information about their willingness to pay money in a utilitytheoretic framework (Larson et al. 2004). In addition to a travel cost model, one can also develop a separate model of transportation mode choice to estimate the value of travel time, providing information on how time is valued versus the cost of travel (Hausman et al. 1995).
} 
In particular, our DCE was not consequential (Vossler et al. 2012), it relayed on epsilon truthfulness and hence did not satisfy the incentive compatibility conditions (Carson and Groves 2007) and did not satisfy several other recommendations for stated preference studies (Champ et al. 2017; Johnston et al. 2017). As a result, we are unable to claim, that the estimated VTTS are unbiased. How to incorporate VTTS questions in a DCE component of a TCM survey remains an important area for future research (not only in the case of our study, but transport literature in general). Second, the hourly 'wage rates' that we used for comparisons were calculated on the basis of household income per adult. It remains an open question if household or individual income should be considered, as the basis for consumers' purchasing decisions in the context of time savings. Finally, our study applied a single-site version of the TCM. Following Von Haefen (2002), all substitute sites are captured in the constant of our model. We acknowledge this as a possible limitation of our study. $^{20}$

Many applied researchers are rather conservative in their assumptions about how much the opportunity cost of time might add to the value of a visited site and preferred to use the lower bounds of the wage rate (Neher et al. 2013). For example, Hynes et al. (2009) suggested that it would be useful to determine individual opportunity costs of travel time to avoid a potential bias related to assuming an excessively high wage fraction as a reference. Meanwhile, a comparison of our approach with the key alternative specifications of the opportunity cost of time show that recreationists may actually value their time higher than it has been expected so far. Consumer surplus calculated with the RP-MXL model was more than twice as high as in the case of not including the travel time at all, or when the opportunity cost of travel time was assumed to be $1 / 3$ of the wage rate. It was even higher than if the opportunity cost of travel time equaled full wage rate of those who did not say they wished their journey had been shorter.

More broadly, our study indicates a need to incorporate various components of the travel cost and to do so in a respondent-specific way. Indeed, travel is a complex issue, especially when related to recreational purposes, and it bears many unmeasured qualities which may be differently perceived and valued by the different travelers (Salomon and Mokhtarian 1998). Our study shows an opportunity to integrate different valuation methods and thus practically use the fact that they refer to different issues and can provide complementary information. Our empirical illustration of valuing recreational birdwatching in a stork village demonstrates the feasibility of this approach. It also shows that, as the minimum, future studies could directly ask respondents if they wish their journey was shorter, and include value of travel time of only those who agreed. In our case, and in line with Jara-Díaz et al. (2008) and Lloyd-Smith et al. (2019), those who were willing to pay to make their journey shorter declared WTP per hour on average close to their full wage rate, although more evidence is needed to verify if this finding is universal.

Acknowledgements The data used in this study was collected in a project funded by the Polish National Science Centre (Grant N N112 29233)9. We thank the participants of the European Association of Environmental and Resource Economists' conference, Toulouse, June 2013 for their helpful comments on an earlier version of this paper. Mikołaj Czajkowski gratefully acknowledges the support of the National Science Centre of Poland (Sonata Bis, 2018/30/E/HS4/00388).

\footnotetext{
${ }^{20}$ We considered including other 'stork villages' in the analysis, but the second most popular and recognized such site (Kłopot) is located $600 \mathrm{~km}$ away, on the opposite side of Poland.
} 
Open Access This article is distributed under the terms of the Creative Commons Attribution 4.0 International License (http://creativecommons.org/licenses/by/4.0/), which permits unrestricted use, distribution, and reproduction in any medium, provided you give appropriate credit to the original author(s) and the source, provide a link to the Creative Commons license, and indicate if changes were made.

\section{References}

Adamowicz W, Louviere J, Williams M (1994) Combining revealed and stated preference methods for valuing environmental amenities. J Environ Econ Manag 26(3):271-292

Agrawal AW, Schlossberg M, Irvin K (2008) How far, by which route and why? A spatial analysis of pedestrian preference. J Urban Des 13(1):81-98

Alberini A, Longo A (2006) Combining the travel cost and contingent behavior methods to value cultural heritage sites: evidence from Armenia. J Cult Econ 30(4):287-304

Alberini A, Zanatta V, Rosato P (2007) Combining actual and contingent behavior to estimate the value of sports fishing in the Lagoon of Venice. Ecol Econ 61(2-3):530-541

Allenby GM, Rossi PE (1998) Marketing models of consumer heterogeneity. J Econom 89(1-2):57-78

Álvarez-Farizo B, Hanley N, Barberán R (2001) The value of leisure time: a contingent rating approach. J Environ Plan Manage 44(5):681-699

Amoako-Tuffour J, Martínez-Espiñeira R (2012) Leisure and the net opportunity cost of travel time in recreation demand analysis: an application to Gros Morne National Park. J Appl Econ 15(1):25-49

Anable J, Gatersleben B (2005) All work and no play? The role of instrumental and affective factors in work and leisure journeys by different travel modes. Transp Res Part A Policy Pract 39(2):163-181

Bartczak A, Lindhjem H, Navrud S, Zandersen M, Żylicz T (2008) Valuing forest recreation on the national level in a transition economy: the case of Poland. For Policy Econ 10(7-8):467-472

Bartczak A, Englin J, Pang A (2012) When are forest visits valued the most? An analysis of the seasonal demand for forest recreation in Poland. Environ Resour Econ 52(2):249-264

Becker GS (1965) A theory of the allocation of time. Econ J 75(299):493-517

Bockstael NE, Strand IE, Hanemann WM (1987) Time and the recreational demand model. Am J Agric Econ 69(2):293-302

Börjesson M, Eliasson J (2014) Experiences from the Swedish value of time study. Transp Res Part A Policy Pract 59:144-158

Bovy PH, Stern E (2012) Route choice: wayfinding in transport networks-wayfinding in transport networks. Springer, Berlin

Broach J, Dill J, Gliebe J (2012) Where do cyclists ride? A route choice model developed with revealed preference GPS data. Transp Res Part A Policy Pract 46(10):1730-1740

Cameron TA (1992a) Combining contingent valuation and travel cost data for the valuation of nonmarket goods. Land Econ 68(3):302-317

Cameron TA (1992b) Nonuser resource values. Am J Agric Econ 74(5):1133-1137

Carson R, Czajkowski M (2014) The discrete choice experiment approach to environmental contingent valuation. Edward Elgar Publishing, Cheltenham

Carson RT, Czajkowski M (2019) A new baseline model for estimating willingness to pay from discrete choice models. J Environ Econ Manag 95:57-61

Carson RT, Groves T (2007) Incentive and informational properties of preference questions. Environ Resour Econ 37(1):181-210

Casey JF, Vukina T, Danielson LE (1995) The economic value of hiking: further considerations of opportunity cost of time in recreational demand models. J Agric Appl Econ 27(2):658-668

Cesario FJ (1976) Value of time in recreation benefit studies. Land Econ 52(1):32-41

Champ PA, Boyle KJ, Brown TC (2017) A primer on nonmarket valuation. Springer, Amsterdam

Chavas J-P, Stoll J, Sellar C (1989) On the commodity value of travel time in recreational activities. Appl Econ 21(6):711-722

Chib S, Greenberg E, Winkelmann R (1998) Posterior simulation and Bayes factors in panel count data models. J Econom 86(1):33-54

Clawson M, Knetsch JL (1966) Economics of outdoor recreation. The Johns Hopkins University Press for Resources for the Future, Washington

Czajkowski M, Giergiczny M, Kronenberg J, Tryjanowski P (2014) The economic recreational value of a white stork nesting colony: a case of 'stork village' in Poland. Tour Manag 40:352-360

Czajkowski M, Ahtiainen H, Artell J, Budziński W, Hasler B, Hasselström L, Meyerhoff J, Nõmmann T, Semeniene D, Söderqvist T, Tuhkanen H, Lankia T, Vanags A, Zandersen M, Żylicz T, Hanley N 
(2015) Valuing the commons: an international study on the recreational benefits of the Baltic Sea. J Environ Manage 156:209-217

Czajkowski M, Zandersen M, Aslam U, Angelidis I, Becker T, Budziński W, Zagórska K (2018) Recreational value of the baltic sea: a spatially explicit site choice model accounting for environmental conditions. Working Paper 11/2018 (270), Faculty of Economic Sciences, University of Warsaw, Poland

Davis AF, Moeltner K (2010) Valuing the prevention of an infestation: the threat of the New Zealand Mud Snail in Northern Nevada. Agric Resour Econ Rev 39(1):56-74

DeSerpa AC (1971) A theory of the economics of time. Econ J 81(324):828-846

Egan KJ, Herriges JA, Kling CL, Downing JA (2009) Valuing water quality as a function of water quality measures. Am J Agric Econ 91(1):106-123

Englin J, Cameron TA (1996) Augmenting travel cost models with contingent behavior data. Environ Resour Econ 7(2):133-147

Englin J, Shonkwiler JS (1995) Modeling recreation demand in the presence of unobservable travel costs: toward a travel price model. J Environ Econ Manag 29(3):368-377

Evans AW (1972) On the theory of the valuation and allocation of time. Scott J Polit Econ 19(1):1-17

Feather P, Shaw WD (1999) Estimating the cost of leisure time for recreation demand models. J Environ Econ Manag 38(1):49-65

Ferrini S, Scarpa R (2007) Designs with a priori information for nonmarket valuation with choice experiments: a Monte Carlo study. J Environ Econ Manag 53(3):342-363

Fezzi C, Bateman IJ, Ferrini S (2014) Using revealed preferences to estimate the value of travel time to recreation sites. J Environ Econ Manag 67(1):58-70

Fleming CM, Cook A (2008) The recreational value of Lake McKenzie, Fraser Island: an application of the travel cost method. Tour Manag 29(6):1197-1205

Fletcher JJ, Adamowicz WL, Graham-Tomasi T (1990) The travel cost model of recreation demand: theoretical and empirical issues. Leis Sci 12(1):119-147

Garrod G, Willis KG (1999) Economic valuation of the environment: methods and case studies. Edward Elgar, Cheltenham

Gawrońska G, Gawroński K, Dymek D, Sankowski E, Harris B (2018) Economic valuation of high natural value areas in central roztocze. Acta Scientiarum Polonorum. Formatio Circumiectus 17(4):45

Gelman A, Carlin JB, Stern HS, Rubin DB (2003) Bayesian data analysis, 2nd edn. Chapman and Hall/ CRC, Boca Raton

Gürlük S, Rehber E (2008) A travel cost study to estimate recreational value for a bird refuge at Lake Manyas, Turkey. J Environ Manag 88(4):1350-1360

Hanemann WM (1984) Welfare evaluations in contingent valuation experiments with discrete responses. Am J Agric Econ 66(3):332-341

Hanley N, Barbier EB (2009) Pricing nature. Cost-benefit analysis and environmental policy. Edward Elgar, Cheltenham

Hanley N, Bell D, Alvarez-Farizo B (2003) Valuing the benefits of coastal water quality improvements using contingent and real behaviour. Environ Resour Econ 24(3):273-285

Hausman JA, Leonard GK, McFadden D (1995) A utility-consistent, combined discrete choice and count data model assessing recreational use losses due to natural resource damage. J Public Econ 56(1):1-30

Hellerstein D, Mendelsohn R (1993) A theoretical foundation for count data models. Am J Agric Econ 75(3):604-611

Huber J, Train K (2001) On the similarity of classical and Bayesian estimates of individual mean partworths. Market Lett 12(3):259-269

Huhtala A, Lankia T (2012) Valuation of trips to second homes: Do environmental attributes matter? J Environ Plann Manage 55(6):733-752

Hynes S, Hanley N, O'Donoghue C (2009) Alternative treatments of the cost of time in recreational demand models: an application to whitewater kayaking in Ireland. J Environ Manage 90(2):1014-1021

Jara-Díaz SR, Munizaga MA, Greeven P, Guerra R, Axhausen K (2008) Estimating the value of leisure from a time allocation model. Transp Res Part B Methodol 42(10):946-957

Johnson MB (1966) Travel time and the price of leisure. Econ Inq 4(2):135-145

Johnston RJ, Boyle KJ, Adamowicz W, Bennett J, Brouwer R, Cameron TA, Hanemann WM, Hanley N, Ryan M, Scarpa R, Tourangeau R, Vossler CA (2017) Contemporary guidance for stated preference studies. J Assoc Environ Resour Econ 4(2):319-405

Kulczyk S, Derek M, Woźniak E (2016) How much is the "wonder of nature" worth? The valuation of tourism in the great Masurian lakes using travel cost method. Ekonom Środowisko 4:235-249

Larson DM, Lew DK (2005) Measuring the utility of ancillary travel: revealed preferences in recreation site demand and trips taken. Transp Res Part A Policy Pract 39(2):237-255 
Larson DM, Lew DK (2014) The opportunity cost of travel time as a noisy wage fraction. Am J Agric Econ 96(2):420-437

Larson DM, Shaikh SL, Layton D (2004) Revealing preferences for leisure time from stated preference data. Am J Agric Econ 86(2):307-320

Lindhjem H, Navrud S (2009) Asking for individual or household willingness to pay for environmental goods? Environ Resour Econ 43(1):11-29

Lloyd-Smith P, Abbott JK, Adamowicz W, Willard D (2019) Decoupling the value of leisure time from labor market returns in travel cost models. J Assoc Environ Resour Econ 6(2):215-242

Lyons G, Urry J (2005) Travel time use in the information age. Transp Res Part A Policy Pract 39(2):257-276

McConnell KE (1975) Some problems in estimating the demand for outdoor recreation. Am J Agric Econ 57(2):330-334

McFadden D (1976) The revealed preferences of a government bureaucracy: empirical evidence. Bell J Econ 7(1):55-72

McFadden D, Train K (2000) Mixed MNL models for discrete response. J Appl Econom 15(5):447-470

Milakis D, Cervero R, van Wee B, Maat K (2015) Do people consider an acceptable travel time? Evidence from Berkeley, CA. J Transp Geogr 44:76-86

Mokhtarian PL (2005) Travel as a desired end, not just a means. Transp Res Part A Policy Pract 39(2):93-96

Mokhtarian PL, Salomon I (2001) How derived is the demand for travel? Some conceptual and measurement considerations. Transp Res Part A Policy Pract 35(8):695-719

Morris EA, Guerra E (2015) Mood and mode: Does how we travel affect how we feel? Transportation 42(1):25-43

Mouter N, Chorus C (2016) Value of time: a citizen perspective. Transp Res Part A Policy Pract 91:317-329

Neher C, Duffield J, Patterson D (2013) Valuation of national park system visitation: the efficient use of count data models, meta-analysis, and secondary visitor survey data. Environ Manage 52(3):683-698

Ory DT, Mokhtarian PL (2005) When is getting there half the fun? Modeling the liking for travel. Transp Res Part A Policy Pract 39(2):97-123

Ovaskainen V, Neuvonen M, Pouta E (2012) Modelling recreation demand with respondent-reported driving cost and stated cost of travel time: a finnish case. J For Econ 18(4):303-317

Palmquist RB, Phaneuf DJ, Smith VK (2010) Short run constraints and the increasing marginal value of time in recreation. Environ Resour Econ 46(1):19-41

Panasiuk D (2001) Wycena środowiska metodą kosztów podróży w praktyce. Wartość turystyczna Pienińskiego Parku Narodowego. W: Ekonomia a rozwój zrównoważony 2:264-277

Parsons GR (2003) The travel cost model. In: Champ PA, Boyle KJ, Brown TC (eds) A primer on nonmarket valuation. Springer, Netherlands, pp 269-329

Parsons GR (2017) The travel cost model. In: Champ PA, Boyle KJ, Brown TC (eds) A primer on nonmarket valuation. Springer, Netherlands, pp 187-233

Randall A (1994) A difficulty with the travel cost method. Land Econ 70(1):88

Rasouli S, Timmermans H (2014) Activity-based models of travel demand: promises, progress and prospects. Int J Urban Sci 18(1):31-60

Revelt D, Train K (2000) Customer-specific taste parameters and mixed logit: households' choice of electricity supplier. University of California at Berkeley, Berkeley

Rossi PE, McCulloch RE, Allenby GM (1996) The value of purchase history data in target marketing. Market Sci 15(4):321-340

Salomon I, Mokhtarian PL (1998) What happens when mobility-inclined market segments face accessibility-enhancing policies? Transp Res Part D Transp Environ 3(3):129-140

Sartori D, Catalano G, Genco M, Pancotti C, Sirtori E, Vignetti S, Bo C (2014) Guide to cost-benefit analysis of investment projects. Economic appraisal tool for Cohesion Policy 2014-2020

Shaw D (1988) On-site samples' regression: problems of non-negative integers, truncation, and endogenous stratification. Journal of Econometrics 37(2):211-223

Shaw WD (1992) Searching for the opportunity cost of an individual's time. Land Econ 68(1):107

Shrestha RK, Seidl AF, Moraes AS (2002) Value of recreational fishing in the Brazilian Pantanal: a travel cost analysis using count data models. Ecol Econ 42(1-2):289-299

Small KA, Rosen HS (1981) Applied welfare economics with discrete choice models. Econometrica 49(1):105-160

Train KE (2009) Discrete choice methods with simulation, 2nd edn. Cambridge University Press, New York

Von Haefen RH (2002) A complete characterization of the linear, log-linear, and semi-log incomplete demand system models. J Agric Resour Econ 27(2):281-319

Vossler CA, Doyon M, Rondeau D (2012) Truth in consequentiality: theory and field evidence on discrete choice experiments. Am Econ J Microecon 4(4):145-171 
Whitaker B (2015) An unlikely tourist attraction in Poland: storks. The New York Times, 2015-11-19

Wiśniewska A, Budziński W, Czajkowski M (2018) Publicly funded cultural institutions - a comparative economic valuation study. University of Warsaw, Department of Economics working paper no. 22(281)

Wolff H (2014) Value of time: speeding behavior and gasoline prices. J Environ Econ Manag 67(1):71-88

Publisher's Note Springer Nature remains neutral with regard to jurisdictional claims in published maps and institutional affiliations. 